\title{
Soberania e responsabilidade internacional humanitária: avaliando o processo de ajuste normativo no âmbito da $\mathrm{ONU}^{2}$
}

\section{Introdução}

No âmbito da política internacional, o período de Guerra Fria foi responsável por fazer com que o humanitarismo ganhasse dimensão em larga escala. Os anos de 1960 elevaram a temática a patamares sem precedentes. Catástrofes naturais, conflitos interestatais e internos - tendo civis como suas maiores vítimas - alcançaram visibilidade internacional a partir das notícias sonoras e das imagens televisionadas, apelando para uma responsabilidade humanitária que ultrapassasse as fronteiras dos Estados. O humanitário passaria a mobilizar atores - inclusive privados - com pretensões ditas apolíticas (Badie, 2002).

Mas até onde chegaria a pretensa responsabilidade internacional especificamente para conter ou sanar catástrofes humanitárias? Durante o conflito bipolar, não muito longe, se ela se chocasse com a soberania estatal.

Sobretudo após a ascensão dos novos Estados independentes africanos e asiáticos, a soberania - associada ao princípio da não-intervenção - foi reforçada como conjunto normativo basilar da sociedade internacional. Nesse contexto, a ideia de que essa

\footnotetext{
1 Doutor em Ciência Política pela Universidade Federal de Pernambuco. Professor do Departamento de Ciência Política da Universidade Federal de Pernambuco, Recife,PE, Brasil.E-mail:mik_lucas@hotmail.com.

2 Este artigo é uma versão aprimorada de um dos capítulos da minha tese de doutorado, defendida no Programa de Pós-Graduação em Ciência Política (Área de Concentração: Relações Internacionais) da UFPE. Agradeço ao meu orientador, Marcelo Medeiros, e ao meu coorientador, Kai Kenkel, por seus suportes ao longo da pesquisa.
} 
sociedade teria alguma responsabilidade sobre a forma com que Estados tratariam seus cidadãos era entendida como normativamente ilegítima quando competisse com questões sensíveis à soberania tradicional (Wheeler, 2000).

De fato, a noção de que o tratamento de civis seria um assunto exclusivamente interno dos Estados, tendo em vista a ótica vestfaliana de soberania, nunca foi absoluta. Durante o século XIX, por exemplo, havia no âmbito da sociedade europeia uma espécie de direito de ingerência, o qual apelava para uma responsabilidade das potências ocidentais para proteger civis em regiões não-ocidentais - de modo geral, brancos e cristãos -, inclusive estrangeiros ${ }^{3}$.

No plano do Direito Internacional, a proteção dos indivíduos passou a ser sistematicamente inserida no seu arcabouço normativo a partir do século XX. Um processo que não obstante esparso nas primeiras décadas, foi robustecido no nível global no pós-II Guerra Mundial por uma sequência documentos internacionais, notadamente a Carta da ONU (1945), a Declaração Universal de Direitos Humanos (1948) e os Pactos sobre Direitos Civis e Políticos e Direitos Econômicos Sociais e Culturais (1966). Do mesmo modo, também ampliado por meio dos chamados sistemas regionais de proteção, o que fortaleceu a ideia de que direitos humanos era uma preocupação internacional (Donnelly, 1999).

Todavia, durante a Guerra Fria, a ajuda externa particularmente voltada a questões humanitárias não poderia ultrapassar os limites da soberania. A superioridade desse instituto, que resguardaria os direitos dos governos, era praticamente inquestionável. Mais ainda quando se falasse em alguma espécie de direito de intervenção estrangeira (Finnemore, 2003).

Essa era uma concepção que estressava sobretudo governos dos Estados recém-independentes, receosos de qualquer interferência

3 Foram principalmente os casos de intervenções contra ações repressivas promovidas pelo Império Otomano, tais quais a francesa e russa na guerra da independência da Grécia (1821-1827); a das potências europeias para proteger cristão maronitas na região da Síria/Líbano (1860-1861); a russa para conter a ação dos otomanos contra os búlgaros (1876-1878); assim como a intervenção coletiva no caso do massacre armênio. Detalhes sobre essas intervenções podem ser vistos na obra de Martha Finnemore (2003). 
nos seus assuntos internos, depois de décadas de submissão colonial. Um exemplo paradigmático disso foi a publicação da resolução 2131 (1965) pela Assembleia Geral da ONU, a chamada "Declaração Sobre a Inadmissibilidade de Intervenção nos Assuntos Domésticos dos Estados e a Proteção de sua Independência e Soberania”, iniciativa tomada por 56 Estados asiáticos, africanos e latino-americanos ${ }^{4}$. A Declaração não dava brecha para qualquer possibilidade de intervenção militar de cunho humanitário (Onuf, 1971). Se a questão humanitária emergia, ela tinha seus limites claros definidos pela soberania tradicional (Wheeler, 2000).

Mas, com o fim do conflito bipolar, a noção rígida de soberania passou a ser questionada quando o assunto era proteção de civis em crises humanitárias domésticas (Glanville, 2014). Diferentemente da versão clássica de soberania na política internacional, a qual prega que a supremacia interna do governo implica na impossibilidade de outros Estados interferirem no modo como governos tratam seus cidadãos - no máximo apenas merecedora de reprovação retórica (Donnelly, 1999) -, passa a ganhar força no contexto político do pós-Guerra fria a ideia de que soberania poderia estar condicionada à forma como governos tratam seus cidadãos. A lógica em torno desse entendimento emergente é a de que a proteção da soberania que um Estado teria no plano internacional deixaria de existir se os governos passassem a cometer abusos contra os direitos fundamentais de seus cidadãos (Hurd, 2011, p. 302). Uma concepção que remete às teorias políticas de base liberal, notadamente a ideia de direito de resistência presente nos contratualismos de autores como Locke e Milton (Bobbio, Mateucci e Pasqualino, 1998, p. 208).

O desafio à versão clássica de soberania, particularmente nos casos de graves violações humanitárias, ascenderia tanto do ponto de vista conceitual/normativo - por meio da atuação de agentes-chave -, como pela prática política internacional. No que concerne

4 A Declaração trata expressamente da proteção dos Estados que tinham se libertado do colonialismo. Foi uma iniciativa do Sul Global, conjunto de Estados que passavam a ganhar maior relevância a partir dos processos de descolonização, principalmente a partir da Conferência de Bandung de 1955, a qual falava na sua declaração final da necessidade de respeito ao princípio da não-intervenção - e que foi ressaltado pela Declaração 2131 (ONU, 1965). 
à prática, são paradigmáticas as chamadas intervenções humanitárias da década de 1990. Surgidas a partir do entendimento emergente que passava a situar conflitos humanitários internos como assuntos de segurança internacional. Quanto ao plano das ideias, pode ser vista a ascensão do conceito de soberania como responsabilidade, que culmina com a institucionalização da Responsabilidade de Proteger ( $\left.\mathrm{R}_{2} \mathrm{P}^{5}\right)$ na ONU. A emergência da R2P torna-se fundamental, pois ela busca estruturar normativamente a relação entre soberania e responsabilidade internacional.

Contudo, esse processo de avanço não é harmônico. Ele é permeado por resistências de países receosos quanto a qualquer relativização normativa da soberania que possa abrir espaços para ingerências externas. Desse modo, países em desenvolvimento podem ser vistos como atores de contenção ${ }^{6}$. Assim, o objetivo deste trabalho é mapear a evolução do processo de ajuste institucional-normativo entre responsabilidade internacional em crises humanitárias e soberania, rastreando os movimentos de contenção de Estados do Sul Global no tocante ao uso da força.

$\mathrm{O}$ artigo possui três metas específicas. A primeira delas é descrever a emergência da ideia de que crises humanitárias internas são assunto de segurança internacional, passíveis de intervenção externa, no âmbito do Conselho de Segurança das Nações Unidas. A segunda visa descrever sistematicamente o processo de evolução institucional da R2P dentro da ONU, até a sua consolidação. A terceira cuida em identificar os movimentos de resistência ao longo do período estudado, a partir das contestações advindas de Estados do Sul Global ${ }^{7}$, no tocante ao uso da força. As duas são alcançadas nas duas seções seguintes desse trabalho. Já a terceira permeia toda o estudo.

\footnotetext{
5 Abreviação do termo em inglês: Responsibility to Protect.

6 Estados do Sul Global, sobretudo as chamadas potências emergentes, são vistos como contestadores de movimentos feitos pelas potências ocidentais, principalmente no que tange aos elementos normativos que envolvem a soberania. Para detalhes sobre esse fenômeno, ver trabalho de Pu (2012).

7 Dentre os Estados do Sul Global, uma atenção particular será dada às potências que compõem hoje - BRICS, por causa de seu poder mais expressivo dentro desse grupo de Estados, com capacidade de influenciar a governança global.
} 
Por meio de um desenho de pesquisa qualitativo, este artigo levanta os principais documentos (relatórios, resoluções e posicionamentos) presentes no processo estudado, triangulando suas informações com o aporte de fontes secundárias. Em cada etapa, são utilizados documentos encontrados tanto de modo indutivo, como pelo direcionamento dado pela literatura. Por focar em uma construção eminentemente empírica, este artigo não está interessado em debates teóricos. Todavia, pode-se dizer que, teoricamente, ele encontra-se lastreado em uma literatura que está embasada majoritariamente na chamada Teoria Política da Sociedade Internacional - comumente conhecida por pesquisadores da subárea de Relações Internacionais como Escola Inglesa (Jackson, 1995; Jackson e Sorensen, 2007).

Ao final, é possível ter uma visão geral estruturada de todo o processo que perpassa o ajuste entre responsabilidade internacional em conflitos humanitários e soberania, culminando com a consolidação institucional da R2P; em meio a movimentos de resistência a partir do Sul Global. Essa pesquisa proporciona uma melhor compreensão de um fenômeno que, apesar de sua relevância, ainda é pouco explorado pela literatura acadêmica em língua portuguesa.

\section{A ascensão da responsabilidade internacional em crises humanitárias no Conselho de Segurança da ONU}

Com o fim da Guerra Fria, um dos aspectos mais significativos de mudança foi o destravamento do Conselho de Segurança da ONU (CSNU). Os números, por si só, revelam o aumento da participação do órgão: nos primeiros 40 anos do Conselho, 14 missões de paz foram estabelecidas. Só entre 1988-89, 5 foram criadas. De 1946-1989 o CSNU havia deliberado 646 resoluções, entre 19901999, foram 638. Durante a Guerra Fria, o CSNU estabeleceu 24 resoluções fundamentadas no capítulo VII da Carta (que autoriza o uso da força), só em 1993 elas foram 27 (Glanville, 2014, p. 181).

Essa participação maior do CSNU não foi apenas quantitativa, mas também qualitativa. Temas que antes escapavam aos debates no âmbito do Conselho passaram a ser objeto de suas resoluções. 
Um dos aspectos novos na sua agenda foi justamente a ideia de que violações massivas de direitos humanos poderiam ser interpretadas como assunto de segurança internacional. Alguns desses casos, inclusive, culminaram com a autorização do uso da força com justificativa exclusivamente centrada na proteção de civis. Esse fato avivou discussões sobre soberania, de um lado, e proteção dos direitos humanos, de outro - tensão que remete também à ideia de securitização de novos temas, trazida pelos Estudos Internacionais de Segurança da chama Escola de Copenhague (Buzan e Hansen, 2009; Buzan, 2015).

O primeiro caso de destaque nesse sentido foi a ação realizada no Iraque. Logo após a Guerra do Golfo, Estados Unidos, França e Grã-Bretanha agiram por meio da operação Provide Comfort, visando proteger sobretudo curdos que estavam sendo reprimidos pelo governo de Saddam Hussein. As principais medidas foram a criação de safe-havens (enclaves protetivos) e no-fly zones (zonas de restrição aérea). A ação teve como fundamento a resolução 688 do Conselho de Segurança (Wheeler, 2000, p. 141-143).

Essa foi a primeira vez em que a proteção de civis em conflitos internos foi vista explicitamente pelo Conselho como assunto de segurança internacional. Por isso, ela pode ser entendida como paradigmática no tocante ao debate envolvendo soberania e proteção dos direitos humanos - mesmo considerando que a deliberação foi literal ao afirmar a necessidade de respeito à soberania e integridade territorial do Iraque (ONU, 1991).

O texto da resolução, após ressaltar seus deveres no tocante à paz e segurança internacionais, revela a motivação central do documento: a) "gravely concerned by the repression of the Iraqi civilian population (...)" e b) "deeply disturbed by the magnitude of the human suffering involved"s (ONU, 1991, p. 31).

Vale ressaltar, no entanto, que os Estados que debateram a resolução intencionalmente decidiram por não utilizar qualquer argumento no texto que pudesse ser interpretado como uma autorização

8 Tradução livre: a) gravemente preocupado com a repressão à população civil iraquiana (...); b) profundamente perturbado com a magnitude do sofrimento humano". 
para uso da força. Entendia-se que isso poderia criar um perigoso precedente. Assim, os dois membros permanentes não-ocidentais (P2), China e Rússia, se abstiveram na votação da resolução 688 e deixaram claro que vetariam qualquer proposta que fosse fundamentada no cap. VII. (Glanville, 2014).

A res. 688 foi o primeiro precedente advindo da prática política internacional que procurou compatibilizar, no pós-Guerra Fria, proteção de civis em crises humanitárias com a soberania. A partir dela, diversas outras resoluções ainda mais representativas foram deliberadas. Estas as quais foram, efetivamente, fundamentadas no cap. VII da Carta e autorizavam expressamente o uso da força. Por causa dessas decisões, os anos de 1990 passaram a ser conhecidos como a década das intervenções humanitárias (Kaldor, 2007).

Nesse sentido, é importante ressaltar a intervenção realizada na Somália. Na ocasião, o Conselho autorizou pela primeira vez uma resolução que previa a possibilidade do uso da força com base no cap. VII, com o intuito de sanar a crise humanitária no país africano. Dentre outros aspectos, o texto da resolução é muito importante porque 1) relaciona de forma inequívoca segurança internacional e crise humanitária: “(...) the magnitude of the human tragedy caused by the conflict in Somalia, further exacerbated by the obstacles being created to the distribution of humanitarian assistance, constitutes a threat to international peace and security" e 2) autoriza o uso da força com base nesse fundamento: "(...) action under Chapter VII of the Charter of the United Nations should be taken in order to establish a secure environment for humanitarian relief operations in Somalia as soon as possible"10 (ONU,1992b, p. 02).

$\mathrm{Na}$ ocasião, Rússia e China decidiram evitar o uso do veto. Mas isso não significou uma completa aquiescência. A China, por exemplo, votou a favor da resolução, mas deixou claro sua

9 Tradução livre:"(..) a magnitude da tragédia humana causada pelo conflito na Somália, exacerbada pelos obstáculos que estão sendo criados para a distribuição da assistência humanitária, constitui uma ameaça à paz e a segurança internacionais".

10 Tradução livre: "Ações com base no Capítulo VII da Carta das Nações Unidas devem ser tomadas o quanto antes com o intuito de estabelecer um ambiente seguro para operações de alívio humanitário na Somália". 
preocupação com o fato de esta ser utilizada para se tomarem ações militares (ONU, 1992d).

No tocante às questões envolvendo soberania, apesar de simbólico, o caso não foi tão problemático. Na Somália, não existia um governo soberano efetivo que pudesse ter supostamente seus direitos violados. A própria Rússia destacou que a situação era um caso que necessitava de uma coalização militar internacional (ONU, 1992d).

A resolução teve votação unânime, os 15 membros do Conselho foram favoráveis (ONU, 1992d). No entanto, alguns Estados procuraram evidenciar a excepcionalidade da situação na reunião 3145 do CSNU, que votou a resolução 794. A China, por exemplo, enfatizou a excepcionalidade da operação militar, pois o caso da Somália era único (ONU, 1992d).

De qualquer modo, a partir de então, o CSNU confirmou a ideia de que crises humanitárias domésticas seriam assuntos de segurança internacional, inclusive podendo-se utilizar a força exclusivamente com o intuito de sanar uma situação desse tipo. Não obstante, isso não significou um novo modus operandi da sociedade internacional, no sentido de que ela responderia prontamente em qualquer situação análoga.

Os casos da Bósnia e de Ruanda podem ser inseridos no grupo de ações tardias. Ambos tiveram autorização para operações dadas pelo Conselho, porém as intervenções ocorreram só após o agravamento das respectivas crises. No primeiro caso, a operação só foi concretizada depois que o governo de Milosevic colocou em prática um programa de limpeza étnica, tendo como símbolo os ataques à cidade Bósnia de Srebrenica (ONU, 1992a) ${ }^{11}$. O conflito teve início em 1992, mas apenas três anos depois uma ação intervencionista foi tomada pela OTAN, a qual concentrou-se em ataques aéreos (Morris, 2006).

O caso de Ruanda foi ainda mais sintomático. Em abril de 1994, o governo do Estado iniciou um processo de extermínio da minoria

11 A resolução que fundamentou a intervenção foi a 770 . Ela foi estabelecida em 1992, mas por falta de disposição em intervir, só foi levada a cabo em 1995. 
étnica Tutsi e dos Hutus moderados ${ }^{12}$. Diversas informações sugeriam a existência de um plano de genocídio ${ }^{13}$, mas o impasse acerca de quem deveria intervir inviabilizou a frustração do projeto de extermínio. Em cerca de três meses, o Estado teve mais de 800 mil pessoas assassinadas. Apenas em julho do mesmo ano é que uma operação foi autorizada, com base na resolução 929 do CSNU (Wheeler, 2000, p. 231).

Não obstante os problemas evidenciados, esses dois casos são importantes porque confirmam uma certa aceitação quanto à possibilidade de ações coercitivas visando a proteção de civis por parte de potências não-ocidentais ${ }^{14}$. Tanto no caso específico da Bósnia, como em Ruanda, a Rússia votou a favor da resolução juntamente com os membros permanentes ocidentais $\left(\mathrm{P} 3^{15}\right)$. Já a China se absteve em ambos. Na resolução 929, o Brasil, que também estava presente, se absteve (ONU, 1994). Já na resolução 770, a Índia seguiu a abstenção chinesa (ONU, 1992c) ${ }^{16}$.

Dentre as crises humanitárias da década de 1990, um dos casos mais sensíveis no tocante à questão entre proteção de civis e a soberania foi a intervenção da OTAN no Kosovo. Trata-se de um episódio paradigmático, considerando o fato de ter ocorrido uma ação sem consentimento explícito do CSNU (Wheeler, 2000).

12 O conflito entre essas duas etnias foi uma herança colonial. Os belgas, que administraram o Estado até sua independência, utilizaram a estratégia de dividir para governar, concedendo privilégios à minoria Tutsi em detrimento da maioria Hutu. Quando Ruanda adquiriu a independência o ressentimento dos Hutus exacerbou-se nos anos seguintes até chegar ao ápice na referida crise de 1994 (Wheeler, 2000).

13 Essas informações foram trazidas pelo próprio chefe da operação de paz que existia em Ruanda, o general Dallaire, por ONGs, como o Human Rights Watch e até mesmo pela CIA (Wheeler, 2000, p. 216).

14 "potências não-ocidentais" é um termo frequentemente usado em artigos de língua inglesa (non-Western powers). Não é o melhor termo, porém ele será adotado quando se falar de potências fora do eixo eurocêntrico. É um conceito importante, por exemplo, para a Rússia. Dada a pouca adequação no seu enquadramento como potência emergente.

15 P3 é um termo em inglês para permanent 3, as três potências ocidentais com assento permanente no Conselho de Segurança: Estados Unidos, Grã-Bretanha e França. Já P5 é utilizado para os 5 membros permanentes, e P2 para os 2 não-ocidentais: Rússia e China

16 No caso da Ruanda, além de Brasil e China, abstiveram-se também Paquistão, Nigéria e Nova Zelândia. Ao passo que na resolução 770, a abstenção de China e Índia foi acompanhar pelo Zimbábue. Em nenhuma delas houve votos contrários. 
A intervenção foi um segundo capítulo da crise dos Balcãs, já vista desde a operação da OTAN na Bósnia. Nesse episódio, forças militares e paramilitares ligadas a Milosevic cometiam agressões contra os kosovares. Várias resoluções do Conselho procuraram prescrever condutas para as partes - o que vai ao encontro da mudança de perspectiva acerca de crises humanitárias internas como assunto de segurança internacional. Inclusive, aprovou-se a resolução 1199, a qual, porém, não obstante fundamentada no cap. VII da Carta, não permitia o uso da força (Thakur e Weiss, 2009, p. 32).

O que impediu a votação de uma resolução que autorizasse uma intervenção militar dessa vez não foi a falta de vontade de possíveis interventores - já que países como os Estados Unidos e Reino Unido demonstravam disposição para tanto -, mas sim a resistência por parte de potências não-ocidentais. O P2 deixou claro que vetaria qualquer proposta de resolução que tivesse o intuito de autorizar intervenção militar estrangeira (Wheeler, 2000, p. 261).

Mesmo assim, houve uma ação. Como justificativa para o fato de a operação não ter sido autorizada por instrumento específico, usou-se a retórica de que a citada res. 1199 poderia dar a fundamentação necessária. Alguns autores ressaltaram a aplicação do entendimento de ilegal, porém legítimo (Franck, 2003).

Tão logo houve a intervenção da OTAN, uma forte oposição pode ser identificada. As críticas mais enérgicas vieram da Rússia e da Índia, os quais, juntamente com Belarus, propuseram uma resolução condenando as ações. O texto do draft qualificava a operação como uma ameaça à paz e a segurança internacionais. A proposta demandava o fim dos ataques e o retorno das negociações. No entanto, ela foi rejeitada por ampla maioria, tendo votos a favor apenas dos três proponentes, com os outros 12 votos contrários (inclusive o do Brasil) (ONU, 1999b) ${ }^{17}$.

17 Vale lembrar que o Conselho de Segurança é composto por 15 membros, dentre os quais 5 são permanentes (Rússia, China, Estados Unidos, Grã-Bretanha e França) e outros 10 são rotativos, eleitos para um mandato de 2 anos (art. 23.2. da Carta da ONU). 
$\mathrm{Na}$ reunião que discutiu a proposta, no entanto, foi possível perceber diferentes tipos de oposição no P2. Enquanto a Rússia afirmava que a intervenção militar da OTAN era uma verdadeira ameaça à paz e à segurança internacionais (como proposto no draft), a China utilizou um argumento mais brando, ressaltando os problemas advindos dos danos causados pela ação e a necessidade de negociações pacíficas (ONU, 1999b).

O fato é que todos esses casos evidenciam um processo de mudança nas estruturas normativas no âmbito da $\mathrm{ONU}^{18}$. Questões humanitárias passaram a ser consideradas assuntos de segurança internacional, que demandavam ações, inclusive com a possibilidade de uso da força - o que teve implicações para o entendimento tradicional acerca da soberania e do princípio da não-intervenção. Ascendia não apenas a ideia de responsabilidade internacional para esse tipo de crise, mas que intervenções militares se tornavam uma faculdade normativa.

Por outro lado, verificou-se que tal fenômeno não ocorre sem resistência. A atitude de questionadores-chave nesse processo ficou mais evidente no caso kosovar. Se se demonstrou com ele a emergência da possibilidade de ação internacional para proteção dos direitos humanos em crises humanitárias internas, ficou claro também que uma relativização a elementos sensíveis da soberania não ocorreria sem contestação.

De qualquer modo, essas práticas deram suporte ao ajuste institucional-normativo. O que implicaria rever atributos da ideia tradicional de soberania. Esse processo iniciou-se concomitantemente com a maior atuação da sociedade internacional nas crises humanitárias e ganhou impulso no início dos anos 2000, como será retratado na próxima seção.

18 Não é objetivo deste trabalho deter-se a elementos teóricos sobre mudanças de entendimentos normativos em ambientes institucionais nas Relações Internacionais. Nesse sentido, sugere-se ao leitor o trabalho seminal de Finnemore e Sikkink (1998). 


\section{A Evolução Institucional da R2P}

Os novos ajustes entre soberania e a ideia de responsabilidade internacional em conflitos humanitários não foram impulsionados apenas pelas práticas e resoluções do Conselho de Segurança, eles também foram reforçados no plano das ideias. Esse processo culminou com a institucionalização da Responsabilidade de Proteger. Essa segunda seção mapeia a referida evolução institucional dessa norma política e seus desafios. Ela está dividida em três subseções: emergência, institucionalização e consolidação e desafios.

\section{Emergência}

Simultaneamente às ações autorizadas pelo Conselho, atores da academia e da sociedade civil procuraram contribuir com o processo de ajustamento teórico entre responsabilidade internacional e proteção de civis em conflitos domésticos, com implicações diretas ao instituto da soberania. Gareth Evans (2008, p. 32-38) destaca algumas ideias promovidas ainda na década de 1990, as quais ajudaram nesse processo:

a) droit d'ingérence humanitaire, uma versão francesa da ideia de intervenção humanitária, que teve como autor Bernard Kouchner (1987). Ganhou força durante a crise na Somália, mas não conseguiu superar a desconfiança do Sul Global à ideia de uso da força para proteção dos direitos humanos como uma forma de imperialismo das potências ocidentais;

b) Segurança Humana (Human Security), apresentada em 1994 pelo documento onusiano Human Development Report: New Dimensions of Human Security, essa concepção procura ser ampla o suficiente para abarcar desde direitos de necessidades básicas como saúde, alimentação, habitação, educação até a questão da intervenção militar, todas interrelacionadas como necessidades e meios para auxiliar Estados em desenvolvimento. O seu principal problema é a amplitude demasiada, dada a dificuldade de visualizar como seria articulada sua 
operacionalização. Mas ela é considerada importante por ser um vetor para mobilizar várias campanhas;

c) Doutrina Blair, direcionada especificamente para a crise no Kosovo, ela procurava justificar a intervenção da OTAN como uma espécie de Guerra Justa. Buscou prever alguns critérios para esse tipo de ação, mas foi criticada por diversos Estados do Sul Global por ser baseada em valores ocidentais, o que despertou novamente a ansiedade do mundo em desenvolvimento;

d) Soberania como responsabilidade, o conceito criado e promovido pelo diplomata sul-sudanês Francis Deng (juntamente com Roberta Cohen, do Brookings Institution) quando estava no cargo de representante do Secretário Geral da ONU para assuntos relacionados a deslocados internos (19922004). A partir desse conceito, vários livros foram publicados. Mesmo tendo menos apelo do que as ideias de direito de ingerência e de segurança humana, serviu diretamente como base para o desenvolvimento da R2P;

e) Soberania individual, trata-se de um conceito cunhado pelo então Secretário Geral Kofi Annan. Ele pretendeu estabelecer a noção de soberania dupla: estatal e individual, sendo que a primeira deveria ser temperada pela segunda (trata-se de uma derivação dos instrumentos de proteção dos direitos humanos). Por meio desse conceito, Annan visava resolver a controvérsia entre soberania $\mathrm{x}$ intervenção, mas a ideia também despertou muito receio entre os Estados do Sul.

Esses conceitos serviram de suporte para o relatório elaborado pela International Comission on Intervention and State Sovereignty (ICISS, 2001). Esse documento buscou promover a noção de que soberania implica também responsabilidade perante nacionais, tanto do próprio Estado, como da sociedade internacional.

Dentre os conceitos ressaltados, provavelmente o mais importante para a Responsabilidade de Proteger foi a própria concepção de soberania como responsabilidade. No âmbito da ONU, as ideias desenvolvidas por Deng foram introduzidas nos discursos de 
Annan. Neles, o então Secretário Geral (SG) convocou a sociedade internacional a debater sobre possíveis saídas para o impasse entre proteção dos direitos humanos e o princípio da não-intervenção. Mas os discursos eram considerados bastante controversos, gerando resistência de Estados em desenvolvimento. A ideia de que proteção dos direitos humanos transcendia a soberania, advogada pelo então SG, causava grande desconforto para os Estados do Sul Global, o que suscitava críticas imediatas de países como China e Rússia (Thakur e Weiss, 2009, p. 33-34). Oposições claras às declarações de Annan surgiram sobretudo de Estados africanos e asiáticos, os quais lutaram para adquirir sua independência soberana durante a Guerra Fria, defendendo firmemente seu direito de não-interferência.

Portanto, para que houvesse uma redefinição da soberania, era necessário estabelecer um conceito que compatibilizasse os anseios dos Estados do Norte e do Sul Globais. Desse modo, o Canadá buscou assumir a função principal de evoluir o debate, funcionando como verdadeiro empreendedor normativo (state champion). $\mathrm{O}$ governo canadense, sob a liderança do ministro das Relações Exteriores Lloyd Axworth, estabeleceu a International Comission on Intervention and State Sovereingty visando solucionar os desafios levantados por Annan.

$\mathrm{Na}$ tentativa de conciliar o Norte e o Sul Globais, a ICISS foi presidida por indivíduos de ambas as regiões: o diplomata australiano Gareth Evans e o argelino Mohamed Sahnoun. Do mesmo modo, também o seu corpo de comissionários tinha composição diversificada ${ }^{19}$. O resultado foi o relatório intitulado The Responsibility to Protect (ICISS, 2001). O objetivo central foi, de fato, reconciliar conceitos como soberania, direitos humanos e intervenção em torno da responsabilidade de proteger.

19 Foram também membros da Comissão: Gisèle Côté-Harper (Canada), Lee Hamilton (Estados Unidos), Michael Ignatieff (Canada), Vladimir Lukin (Rússia), Klaus Naumann (Alemanha), Cyril Ramaphosa (África do Sul), Fidel V. Ramos (Filipinas), Cornelio Sommaruga (Suíça), Eduardo Stein Barillas (Guatemala) e Ramesh Thakur (Índia). 
Assim, os princípios básicos do relatório são amplos. Fala-se de graves violações às populações. Os crimes que ativam a R2P foram estabelecidos apenas de modo exemplificativo:

(1) Basic Principles

A. State sovereignty implies responsibility, and the primary responsibility for the protection of its people lies with the state itself ${ }^{20}$.

B. Where a population is suffering serious harm, as a result of internal war, insurgency, repression or state failure, and the state in question is unwilling or unable to halt or avert it, the principle of non-intervention yields to the international responsibility to protect ${ }^{21}$ (ICISS, 2001, p. XI, grifo nosso)

No relatório, houve um evidente cuidado em distinguir o novo conceito da ideia antiga de intervenção humanitária, tendo em vista o desconforto causado pelo termo aos Estados do Sul Global:

the Commission found that the expression "humanitarian intervention" did not help to carry the debate forward, so too do we believe that the language of past debates arguing for or against a "right to intervene" by one state on the territory of another state is outdated and unhelpful. We prefer to talk not of a "right to intervene" but of a "responsibility to protect" 22 (ICISS, 2001, p. 12).

Por outro lado, mesmo procurando-se evitar a terminologia “intervenção humanitária”, ressaltando sobretudo a necessidade de

20 Tradução livre: "A segurança estatal implica em responsabilidade, e a responsabilidade primária para a proteção dos indivíduos reside no próprio Estado".

21 Tradução livre: "Quando uma população sofre dano grave, como resultado da guerra interna, da insurgência, da repressão ou do fracasso do Estado, e quando o Estado em questão não está disposto a deter ou evitar a situação, o princípio da não intervenção cede a responsabilidade internacional de proteger".

22 Tradução livre:"a Comissão entende que a expressão "intervenção humanitária" não ajudou a levar adiante o debate, também acreditamos que a linguagem dos debates passados, a favor ou conra um "direito de intervenção" por um Estado no território de outro está desatualizada e não ajuda aos debates. Preferimos falar não de um 'direito de intervenção', mas de uma 'responsabilidade de proteger"'. 
prevenção e reconstrução, o foco ainda esteve centrado na intervenção militar. $\mathrm{O}$ relatório traz três dimensões de responsabilidade: a responsabilidade de prevenir (responsibility to prevent), a responsabilidade de agir (responsibility to react) e a responsabilidade de reconstruir (responsibility to rebuild), cada uma ocupando uma seção específica ( 3,4 e 5, respectivamente). A intervenção militar para a proteção de civis seria, em tese, apenas uma das três (a responsabilidade de agir). Não obstante, as partes subsequentes cuidaram primordialmente do problema da intervenção: a questão da autoridade em casos de intervenção (seção 6) e da operação militar (seção 7) (ICISS, 2001) 23. A ICISS demonstrava que, de fato, queria avançar na seara mais sensível envolvendo o instituto da soberania.

Nesse sentido, um dos mecanismos mais controversos foi a possibilidade de autorizar intervenção quando o CSNU estivesse paralisado, por meio da Assembleia Geral, usando o recurso do Uniting for Peace ${ }^{24}$. Como esperado, essa ideia causou apreensão frente a Estados do Sul Global. Celso Amorim, ministro das Relações Exteriores do Brasil na época, ilustrou bem essa preocupação ao afirmar que uma das partes mais controversas do relatório da ICISS seria o problema decorrente do uso da força quando houvesse impasses no CSNU (Stuenkel e Tourinho, 2014, p. 385).

A R2P enfrentou também um problema conjuntural: o fato de seu relatório ter sido publicado pouco tempo depois dos atentados de 11 de setembro. Isso despertou receios de governantes e da comunidade acadêmica de que a nova norma pudesse ser usada na Guerra ao Terror (Glanville, 2014, p. 192). Temores que foram ampliados após a invasão ao Iraque.

De qualquer forma, o instituto foi obtendo espaço no âmbito da sociedade internacional, sobretudo por causa do empenho de empreendedores normativos. Logo após a publicação do relatório,

23 O relatório é divido em 8 seções, a 1 e 2 são basicamente contextualizações e conceitos, ao passo que na 8 há a conclusão do relatório.

24 Mecanismo desenvolvido em 1950, permite que nos casos em que o Conselho de Segurança falhar no seu compromisso de preservar a segurança e a paz internacionais, determinada questão pode ser levada em caráter de urgência para ser votada pela Assembleia Geral (ICISS, 2001). 
membros da ICISS, como Evans e Thakur, passaram a se empenhar em encontros com entidades governamentais, Organizações Internacionais e com a sociedade civil para promover a norma. Do mesmo modo, o governo canadense também ajudou na promoção do relatório (Thakur e Weiss, 2009, p. 35). Se por um lado haveria resistência, do outro, a pressão em prol da norma também ascendia.

O engajamento do Canadá e dos membros da ICISS foi reforçado pela atuação do SG. Em 2003, Annan lançou um fórum de discussão sobre novas ameaças na segurança internacional, intitulado High-Level Panel on Threats, Challenges, and Change (HLP). O relatório A More Security World: Our Share Responsibility foi resultante desse painel. Este documento teve escopo maior do que a Responsabilidade de Proteger (seguindo a linha de segurança humana), mas trouxe consigo preceitos já presentes na R2P.

Uma breve análise de conteúdo demonstra que o termo 'responsibility to protect' aparece nove vezes no corpo do texto. A parte 3 do relatório trata justamente da segurança coletiva e o uso da força. Mais especificamente, no parágrafo 201 da discussão sobre a legalidade do uso da força presente na referida parte, verifica-se explicitamente a inserção dos preceitos basilares da R2P:

The successive humanitarian disasters in Somalia, Bosnia and Herzegovina, Rwanda, Kosovo and now Darfur, Sudan, have concentrated attention not on the immunities of sovereign Governments but their responsibilities, both to their own people and to the wider international community. There is a growing recognition that the issue is not the "right to intervene" of any State, but the "responsibility to protect" of every State when it comes to people suffering from avoidable catastrophe (...) while sovereign Governments have the primary responsibility to protect their own citizens from such catastrophes, when they are unable or unwilling to do so that responsibility should be taken up by the wider international community - with it spanning a continuum 
involving prevention, response to violence, if necessary, and rebuilding shattered societies (... $)^{25}$ (ONU, 2004, p. 65-66).

Com relação à participação de membros dos Estados do Sul Global na elaboração do referido relatório, Gareth Evans (2008) que inclusive também foi um dos membros - destaca a aceitação por parte de Qian Qichen, ex-vice primeiro ministro da China. Para Evans (2008), o grande prestígio de Qian foi determinante para que a China aceitasse a R2P durante o processo de institucionalização na ONU. Vale destacar também a presença de membros do Brasil, Índia e Rússia na composição do painel que elaborou o relatório final (ONU, 2004). Desse modo, busca-se incorporar possíveis Estados resistentes ao processo.

Outro fator importante foi o consenso acerca da R2P nascido no continente africano, durante o processo de criação da União Africana (UA ${ }^{26}$. A UA foi a primeira organização regional a inserir elementos da R2P. Seu ato constitutivo previu que a organização poderia intervir em Estados membros que estivessem passando por graves situações como crimes de guerra, genocídio e crimes contra a humanidade. Por meio desse dispositivo, ela estabeleceu arranjos regionais que foram previstos pela ICISS (Zähringer, 2013, p. 190)

Porém, se de um lado o 'consenso africano' mostrou um significativo apoio advindo de Estados não-ocidentais, no Sul Global esses foram praticamente os únicos que trabalharam na promoção da ideia desenvolvida pelo relatório da ICISS nessa época. Dentre os Estados que futuramente se agrupariam em torno dos BRICS, apenas a África do Sul exerceu função importante na promoção

25 Tradução livre: "As sucessivas catástrofes humanitárias na Somália, Bósnia Herzegovina, Ruanda, Kosovo e agora em Darfur, no Sudão, concentraram a atenção não nas imunidades dos governos soberanos, mas nas suas responsabilidades, tanto para o seu próprio povo como para a comunidade internacional. Há um reconhecimento crescente de que a questão não é o 'direito de intervenção' de qualquer Estado, mas a 'responsabilidade de proteger' de todos os Estados quando pessoas estão sofrendo em catástrofes evitáveis (...), enquanto os governos soberanos têm responsabilidade primária de proteger seus próprios cidadãos de tais catástrofes, quando não conseguem ou não estão dispostos a fazê-lo, a responsabilidade a responsabilidade deve ser assumida pela comunidade internacional em geral - com um contínuo que envolve prevenção, resposta à violência, se necessário, e reconstrução de sociedades destruídas".

26 A UA substituiu em 2002 a Organização da Unidade Africana. 
do conceito na época. Oliver Stuenkel (2014, p. 09-10) lembra que críticas mais fortes foram particularmente lançadas pelos indianos, que desafiavam os argumentos morais e legais que fundamentavam a R2P.

Portanto, fora os africanos, no geral, o Sul Global resistia ao novo conceito. $\mathrm{O}$ que se revelava mais claramente nas objeções advindas das potências não-ocidentais. As tentativas da ICISS de afastar a R2P da intervenção humanitária e conciliá-la com o instituto da soberania não se mostraram tão eficazes de início.

\section{A institucionalização}

$\mathrm{O}$ grande passo para a institucionalização da R2P ocorreu no encontro de 60 anos da ONU, no World Summit (Cúpula Mundial). A norma foi inserida nos parágrafos 138 e 139 do relatório final da Assembleia Geral, o Summit Outcome Document (SOD) (ONU, 2005b), publicado em 15 de setembro de 2005. Menos de 4 anos depois da publicação do relatório final da ICISS, a sociedade internacional institucionalizava a Responsabilidade de Proteger.

Para Alex Bellamy (2006, p. 153), o consenso que culminou posteriormente com a institucionalização da R2P no âmbito da ONU foi derivado de quatro fatores, os três citados anteriormente: 1) o engajamento do governo canadense e dos membros da comissão da ICISS; 2) a adoção da R2P pelo HLP; 3) a emergência do citado consenso africano, além de 4) um relatório escrito em nome dos Estados Unidos por George Mitchell e Newt Gingrich, sobre reforma da $\mathrm{ONU}^{27}$.

Importante ressaltar que a R2P institucionalizada pela Assembleia Geral da ONU (AGNU) não é exatamente a mesma contida no relatório da ICISS (2001). De antemão, dois aspectos principais merecem destaque: 1) o SOD prevê que a R2P apenas cuida dos crimes de limpeza étnica, genocídio, crimes contra a humanidade e crimes de guerra e 2) qualquer intervenção militar deve passar

27 Tratou-se de um relatório que buscava averiguar a compatibilidade entre os interesses dos Estados Unidos e a agenda de reforma então proposta por Kofi Annan, o documento ecoou preceitos da ICISS no tocante a responsabilidade internacional na proteção de civis (Bellamy, 2006, p. 153) 
necessariamente pelo crivo do Conselho de Segurança (ONU, 2005b).

Houve críticas a essa forma restrita institucionalizada pelo documento. Alguns autores chamaram a versão do Summit de "R2P-lite" (Weiss, 2006, p. 750). Para Evans (2008), a questão mais problemática foi o fato de intervenções só poderem ser realizadas havendo a anuência do CSNU. Por outro lado, essa versão reduzida foi importante para facilitar a aceitação no âmbito da Summit.

O objetivo de limitar intervenções ao escrutínio do CSNU foi uma forma de tentar compatibilizar interesses aparentemente inconciliáveis entre Estados Unidos, Grã-Bretanha e França de um lado, e Rússia, China, Índia e países africanos de outro (Bellamy, 2006, p. 166). Essa forma de institucionalização torna-se mais um dado de avanço em meio a movimentos de contenção.

O ponto mais positivo foi a adoção do documento final de forma unânime, considerando o fato de não ter havido votos em contrário. Apesar de não ter criado um instrumento jurídico, a institucionalização na Assembleia Geral revelou um comprometimento político expresso (Welsh, 2014, p. 129). Mas isso não significou homogeneidade perante os Estados. Resistências ao conceito, sobretudo por parte do Sul Global, ainda era algo evidente.

Opiniões críticas de Estados a esse respeito podem ser identificadas em seus posicionamentos durante a aprovação do SOD. A International Coalition for the Responsibility to Protect (ICRtoP) ${ }^{28}$ fez um mapeamento dos discursos dos Estados no qual é possível identificar as posições daqueles que mostraram resistência à R2P: China, Cuba, Egito, Irã, Paquistão, Rússia, Venezuela, Vietnã e Malásia ${ }^{29}$.

28 Trata-se de uma coalização de Organizações Não-Governamentais focada no fortalecimento do consenso normativo em torno da R2P. Para mais informações, ver: http://www.responsibilitytoprotect. org. [Acesso em 10 de julho de 2017].

29 Esses são todos Estados que na categoria embraces R2P que tiveram suas respostas classificadas como "No". Há também outros Estados que não comentaram ou que seus posicionamentos foram classificados como "Unclear". O documento intitulado Chart on the government position on R2P que está disponível em: http://www.responsibilitytoprotect.org/index.php/component/content/ article/35-r2pcs-topics/295-r2pcs-chart-on-government-positions-on-r2p. [Acesso em: 10 de julho de 2017]. 
Assim, no documento disponibilizado pela ICRtoP, é possível ver os principais pontos selecionados nos discursos dos Estados que questionaram a R2P e, ao mesmo tempo, ter uma boa noção entre o bloco de países que rejeita parte da ideia e o que questiona a própria norma em si.

No quadro 1, segue-se a seleção de posicionamentos dos Estados que questionaram a norma durante o Summit. Nele, classifica-se o tipo de rejeição e apresenta-se o resumo da posição assumida pelos nove Estados que tiveram alguma discordância.

\section{Quadro 1 - Contestação da R2P no World Summit}

\begin{tabular}{|c|c|c|}
\hline Estados & Níveis de rejeição & Opinião retirada dos discursos \\
\hline China & Parcial & Necessidade de mais discussões sobre \\
\hline Cuba & Total & $\begin{array}{l}\text { R2P apenas vai servir como suporte para intervenção de } \\
\text { superpotências nos interesses domésticos dos Estados. }\end{array}$ \\
\hline Egito & Total & $\begin{array}{l}\text { Não existe responsabilidade perante civis a não } \\
\text { ser a responsabilidade do próprio Estado }\end{array}$ \\
\hline Irã & Parcial & R2Pé muito vaga \\
\hline Malásia & Parcial & Necessidade de mais discussões sobre R2P \\
\hline Paquistão & Total & $\begin{array}{l}\text { Medidas para proteger civis não podem ser tomadas de } \\
\text { encontro ao princípio da não-intervenção ou questionando } \\
\text { a soberania e a integridade territorial dos Estados }\end{array}$ \\
\hline Rússia & Parcial & $\begin{array}{l}\text { Não há entendimento suficiente acerca da } \\
\text { R2P. A ONU tem condições de responder a tais } \\
\text { eventos sem a necessidade da R2P }\end{array}$ \\
\hline Venezuela & Total & R2P serve apenas para os interesses dos Estados poderosos \\
\hline Vietnã & Total & R2P é a reencarnação da intervenção humanitária \\
\hline $\begin{array}{l}\text { Malásia como representante do Mo- } \\
\text { vimento dos Não-alinhados (MNA) }\end{array}$ & Total & R2P éa reencarnação da intervenção humanitária \\
\hline
\end{tabular}

Fonte: elaboração do autor adaptada do documento produzido pela ICRoP: Chart on the government position on R2P31.

30 Esse posicionamento foi destacado sobretudo para mostrar que dentro de um grupo determinado Estado pode assumir postura diferente da sua individual, como foi o caso da Malásia.

31 Disponível em: disponível em: http://www.responsibilitytoprotect.org/index.php/component/ content/article/35-r2pcs-topics/295-r2pcs-chart-on-government-positions-on-r2p. [Acesso em 12 de novembro de 2016]. 
Dois tipos de discursos podem ser vistos no quadro acima: no primeiro, classificado com rejeição total, Estados opositores (Cuba, Egito, Paquistão, Venezuela, Vietnã e o MNA) afirmam que a R2P é apenas mais uma forma de intervenção humanitária e que serve exclusivamente para legitimar a ingerência de potências sobre assuntos da esfera doméstica de outros Estados. O segundo, classificado aqui como moderado, foca principalmente na imprecisão da norma e necessidade de maiores esclarecimentos sobre seus dispositivos - foi o caso do P2.

Houve ainda declarações de Estados que foram classificadas pela ICRtoP como inconclusivas (unclears), já outros não comentaram. Dentre as potências emergentes, alguns posicionamentos são importantes, pois apontam para certa heterogeneidade. Por exemplo, o Brasil tomou uma posição considerada inconclusiva, a Índia preferiu não comentar sobre a R2P, já a África do Sul se posicionou claramente a favor da norma (acompanhando uma tendência já relatada na UA).

Mesmo após a institucionalização, os debates iniciais na ONU demonstram resistências e uma possibilidade de abandono da R2P logo após sua aceitação. Discussões no âmbito do Conselho de Segurança revelaram posturas negativas no tocante à norma (Bellamy, 2009). Isso ocorreu nos debates sobre proteção de civis em conflitos armados, que visava deliberar uma nova resolução depois de cinco anos ${ }^{32}$.

Na ocasião, potências não-ocidentais - Rússia, China e Brasil juntamente com outros Estados do Sul: Argélia e Filipinas, revelaram resistência para debater a R2P no âmbito do Conselho, afirmando que o SOD apenas havia possibilitado maiores discussões sobre a R2P, e no âmbito da Assembleia Geral. De outro lado, Estados Europeus e outros como Canadá, Japão, Coreia do Sul e africanos apoiaram a visão ocidental (ONU, 2005a).

Foram seis meses de intensas discussões até que finalmente houvesse algum progresso (Stuenkel, 2014, p. 10). Uma mudança 
positiva só surgiu com a nova composição do CSNU tomada no ano seguinte, com a entrada de Estados como Eslováquia, Qatar, Peru, Congo e Gana e a saída de Argélia, Brasil e Filipinas. Essa nova composição resultou na adoção da res. 1674. Ela trouxe, pela primeira vez, a R2P de forma expressa em uma deliberação do Conselho e demonstrou que a nova norma também seria discutida nessa esfera, associada diretamente ao fórum que debate a proteção de civis em conflitos armados.

\section{Consolidação e desafios recentes}

Apesar de a adoção da res. 1674 ter assentado definitivamente a norma na estrutura do CSNU, ela não dissipou a resistência à R2P dentro da ONU. Após a referida resolução, entre 2006 e 2009, o Conselho só se referiu à $\mathrm{R} 2 \mathrm{P}$ em mais duas ocasiões, em uma resolução referente a Darfur e outra novamente no debate sobre proteção de civis em conflitos armados (Welsh, 2014).

No entanto, a partir de 2009, o CSNU passa a citar a R2P em várias resoluções, tanto relacionadas a casos específicos, como em questões mais gerais. Como exemplo de casos específicos, tem-se a resolução 1996 referente ao Sudão do Sul, já como questões mais gerais, vale lembrar a res. 2150 .

A consolidação da R2P na seara da ONU deveu-se, em grande medida, à participação de Ban Ki-moon. Ao assumir o cargo em 2007, o novo SG deu continuidade ao processo iniciado por Annan, procurando avançar no problema da operacionalização da norma. Uma das primeiras medidas tomadas foi a indicação de um conselheiro ligado ao SG específico para a temática: special adviser on the Responsibility to Protect. O cargo foi ocupado primeiramente pelo acadêmico norte-americano Edward Luck. Mais do que isso, foi estabelecido um joint office entre este novo cargo e o special adviser para assuntos relacionados à prevenção do genocídio.

A atuação do SG foi reforçada por networks estabelecidos no seio da sociedade civil. Um exemplo importante foi criação do Global Centre for the Responsibility to Protect (GlobalR2P), em 2008. Fundado por uma junção de governos, experts em direitos 
humanos, e por organizações especializadas ${ }^{33}$, ele surgiu com o objetivo de disseminar a aceitação da norma e contribuir com mecanismos de implementação. No plano acadêmico, a GlobalR2P se destaca por administrar um periódico específico sobre a matéria.

Outra importante criação da sociedade civil foi a já citada International Coalition for the Responsibility to Protect. Estabelecida em 2009 por um grupo de Organizações Não-Governamentais regionais e internacionais, trata-se de uma coalizão composta por ONGs de todas as regiões do planeta, e tem como objetivo fortalecer o consenso normativo referente à $\mathrm{R} 2 \mathrm{P}^{34}$.

O processo de consolidação da norma na ONU passou a ser reforçado a partir de 2009, quando Ban Ki-moon iniciou a publicação de relatórios anuais com o intuito de operacionalizá-la. O relatório intitulado Implementing the Responsibility to Protect foi divulgado em janeiro de 2009, nele destacam-se medidas e os atores empenhados na aplicação da R2P.

O relatório estabelece três pilares: I) a responsabilidade de proteger dos Estados; II) a assistência internacional; III) respostas tempestiva e decisiva da sociedade internacional. $\mathrm{O}$ documento prevê no primeiro pilar a responsabilidade dos Estados para prevenir e responder aos quatro crimes: genocídio, limpeza étnica, crimes contra a humanidade e crimes de guerra. No segundo, enfatiza-se o papel da cooperação dos demais Estados para ajudar outros que estejam em crise, assistência que pode ser tanto intergovernamental, sub-regional e regional, assim como com auxílio da sociedade civil, de setores privados, além da própria ONU - mas de forma pacífica. Por fim, o terceiro pilar disciplina a questão da resposta em tempo e decisiva pela sociedade internacional, podendo ser, em última instância, por meio de intervenção militar (ONU, 2009).

Apesar de organizar os pilares em sequência, Ban Ki-moon deixou claro no relatório que não existe hierarquia entre eles:

33 Compõem essa organização o International Crisis Group, Human Rights Watch, Oxfam International, Refugees International e a WFM-Institute for Global Policy. Mais informações estão disponíveis em: http://www.globalr2p.org. [Acesso em 11 de julho de 2016].

34 Para mais, ver: http://www.responsibilitytoprotect.org/index.php/about-coalition. [Acesso em 15 de julho de 2016]. 
The strategy stresses the value of prevention and, when it fails, of early and flexible response tailored to the specific circumstances of each case. There is no set sequence to be followed from one pillar to another, nor is it assumed that one is more important than another. Like any other edifice, the structure of the responsibility to protect relies on the equal size, strength and viability of each of its supporting pillars (ONU, 2009, p. 02, grifo nosso) $)^{35}$.

Após o relatório do SG, e por recomendação deste, foi estabelecido um fórum de discussão específico para R2P dentro da Assembleia Geral a ser seguido anualmente: The General Assembly Informal Interactive Dialogue (ID). Nele, os Estados se posicionam sobre R2P considerando diversos ângulos, tanto com relação a assuntos específicos como em casos mais gerais - trata-se de uma das principais fontes para entender o posicionamento dos Estados no tocante à norma.

Quadro 2 - Tema dos Diálogos Informais por ano (2009-2016)

\begin{tabular}{l|c}
\hline \multicolumn{1}{c|}{ Título do relatório base } & Ano \\
\hline & 2009 \\
\hline Early warning, assessment and the responsibility to protect & 2010 \\
\hline The role of regional and sub-regional arrangements in implementing the responsibility to protect" & 2011 \\
\hline Responsibility to Protect: Timely and Decisive Response & 2012 \\
\hline Responsibility to Protect: State responsibility and prevention & 2013 \\
\hline Fulfilling our colletive responsibility: International assistance and the responsibility to protect & 2014 \\
\hline A vital and enduring commitment: implementing the responsibility to protect & 2015 \\
\hline Mobilizing collective action: The next decade and the responsibility to protect & 2016 \\
\hline
\end{tabular}

Fonte: elaboração do autor com dados disponíveis em: < http://www.responsibilitytoprotect.org/index.php/about-rtop >. [Acesso em 12 de junho de 2017].

35 Tradução livre:"A estratégia enfatiza o valor da prevenção e, quando falha, uma resposta tempestiva e flexível adaptada às circunstâncias específicas de cada caso. Não há uma sequência definida a seguir de um pilar para outro, nem se supõe que um seja mais importante do que outro. Como qualquer outro edifício, a estrutura da responsabilidade de proteger depende do tamanho, força e viabilidade iguais de cada um dos seus pilares de sustentação". 
Do mesmo modo, em 2009 também foi estabelecida a primeira resolução da AGNU referente à R2P. Foi a res. 308, apresentada pela Guatemala, com o suporte de outros 67 Estados a proposta considerou o relatório do SG sobre implementação da R2P e se comprometeu a continuar os debates sobre a norma ${ }^{36}$.

Os numéricos ilustram o processo de consolidação da R2P no âmbito da ONU. Além dos diálogos anuais na AGNU, a R2P aparece também com frequência em resoluções do CSNU, assim como no Conselho de Direitos Humanos da ONU (CDH). Até meados de 2016, 50 resoluções ${ }^{37}$ do CSNU se referiram a R2P e 16 resoluções $^{38}$ no $\mathrm{CDH}$. Desse modo, em diversos fóruns diferentes, a R2P torna-se uma espécie de ponto focal quando se trata da questão envolvendo responsabilidade internacional em crises humanitárias.

O quadro 3 agrupa os principais documentos no processo de consolidação da R2P:

Quadro 3 - Documentos cruciais no processo de consolidação

\begin{tabular}{c|c|c|c}
\hline Órgão & Documento & Sobre o documento & Ano \\
\hline Assembleia Geral & A/60/L.1 & Summit Outcome Document & 2005 \\
\hline Conselho de Segurança & S/RES. 1674 & $\begin{array}{c}\text { Primeira resolução do } \\
\text { CSNU a versar sobre R2P }\end{array}$ & 2006 \\
\hline Secretário Geral & A/63/677 & $\begin{array}{c}\text { Relatório do SG sobre } \\
\text { implementação da R2P }\end{array}$ & 2009 \\
\hline Assembleia Geral & A/RES/63/308 & $\begin{array}{c}\text { Primeira resolução da AGNU } \\
\text { a tratar diretamente da R2P }\end{array}$ & 2009 \\
\hline
\end{tabular}

Fonte: elaboração do autor a partir dos dados disponíveis em: <http://www.responsibilitytoprotect.org/index.php/about-rtop>. [Acesso em 12 de junho de 2017].

A velocidade com que a R2P ascendeu na ONU é realmente um caso particular. Seu rápido avanço, em comparação a outros casos

36 Informações disponíveis em: http://www.responsibilitytoprotect.org/index.php/about-rtop/the-unand-rtop. [Acesso em: 10 de julho de 2016].

37 Compilação disponível em: http://www.globalr2p.org/media/files/unsc-resolutions-and-statementswith-r2p-table-as-of-august-2016.pdf. [Acesso em: 11 de julho de 2016].

38 Compilação disponível em: http://s156658.gridserver.com/media/files/hrc-resolutions-r2p.pdf. [Acesso em 11 de julho de 2016]. 
(menos de quatro anos da sua publicação até a institucionalização), é notório. Para Luck (2011), não obstante essa significativa velocidade, é preciso considerar o contexto existente hoje. Se se comparar a evolução da R2P com a emergência de outras normas voltadas à proteção dos direitos humanos em meados do século passado, tem de se levar em consideração que há na atualidade um ambiente muito mais favorável.

Contudo, o avanço da R2P não significa estar livre de questionamentos sobre conteúdo ou modo de aplicação - como vem sendo identificado em todo o seu processo. Tal qual relatado, em apenas três meses após a publicação do SOD, já foi possível verificar discursos que rejeitavam a nova norma. E mesmo após a res. 1674 do CSNU, essas contestações não cessaram.

$\mathrm{Na}$ ocasião em que foi criado o cargo de special adviser, resistências nos corredores da ONU vieram novamente à tona. Delegações de Estados africanos, árabes e latino-americanos passaram a falar que, na verdade, o que ocorreu no Summit foi a rejeição da R2P. Para eles, a AGNU não teria aceito a nova norma (Evans, 2008, p. 50).

Em 2009, apesar do clima positivo dos primeiros debates, receios e críticas foram claramente revelados já nos primeiros Diálogos Informais sobre a R2P. Certos Estados do Sul - geralmente os mais antagônicos aos Estados Unidos - mostraram-se mais reticentes, como foi o caso de Cuba, que realçou sua preocupação com a possível associação entre R2P como intervenção humanitária.

Potências não-ocidentais também expressaram suas apreensões. Tal qual os cubanos, os indianos destacaram seu receio sobre associar R2P e intervenção humanitária, bem como um possível mau uso da norma. Brasil lembrou o fato de a norma ser ainda objeto de preocupação de diversos Estados, e que temores e críticas deveriam ser considerados nos debates. A Rússia ressaltou a necessidade de cautela quanto aos avanços na implementação da norma. Já a China sublinhou que, por se tratar de um conceito em evolução que não é parte do direito internacional, os Estados deveriam evitar o uso da R2P como mecanismo de pressão sob outras entidades 
soberanas $^{39}$. Em certa medida, receios como esses continuaram nos debates dos anos seguintes.

Os desafios à R2P se tornaram mais intensos após a intervenção na Líbia. De fato, o episódio foi considerado um momento crítico na evolução da norma (Berti, 2013, p. 25). O então Secretário Geral chegou a afirmar na época que a intervenção marcou a consolidação da R2P (Morris, 2013, p. 1265). Foi a primeira situação em que, de forma incontestável, o CSNU autorizou uma intervenção em um Estado em pleno funcionamento ${ }^{40}$. Porém, as diversas críticas ao procedimento feito na intervenção liderada pela OTAN culminaram com ceticismo para a R2P; sobretudo com os vetos decorrentes para o caso sírio.

Nos debates informais sobre a R2P em 2012, o caso da Líbia tornou-se exemplo negativo determinante utilizado por diversos Estados do Sul para se opor a uma nova ação na Síria. Considerando os membros do BRICS, todos revelaram, de certo modo, ceticismo quanto à ideia do uso da força inserida na norma. Dos cinco Estados, dois mencionaram expressamente o problema da intervenção na Líbia. A África do Sul ressaltou que, levando em consideração a forma como foi utilizada a res. 1973, ela era contra autorização para o uso da força em que não houvesse qualquer accountability. Já a Rússia relacionou de forma ainda mais direta os efeitos negativos da intervenção na Líbia sobre a norma, ao afirmar que o episódio não só falhou em renovar a fé na R2P, como também causou sérios danos ao próprio conceito.

Mesmo com todos os aspectos negativos, a Líbia se torna um divisor de águas nos debates sobre a R2P no CSNU. Desde a institucionalização em 2005, até a intervenção da OTAN, o Conselho de Segurança havia se referido à R2P apenas em quatro ocasiões:

39 Os debates estão disponíveis em: http://www.responsibilitytoprotect.org/index.php/documentarchive/government?view=fjrelated\&id=2409. [Acesso em 12 de julho de 2016].

40 Segundo diversos autores (Berti, 2013; Williams; Bellamy, 2012; Morris, 2013, Weiss, 2014), as intervenções na década de 1990 não tiveram essa característica explícita. Williams e Bellamy (2012) apontam alguns fatos que fundamentam essa afirmação: na intervenção da Somália não existia um governo efetivo central; no Haiti, houve uma autorização por parte do governo, de última hora; em Ruanda, um governo interino autorizou a intervenção tardia na França; em Kosovo, como visto, não houve autorização explicita. 
na resolução 1653, referente a crises humanitárias na República Democrática do Congo e em Burundi; em duas ocasiões no fórum específico sobre proteção de civis em conflitos armados (S/RES1674 e S/RES/1894) e na crise do Darfur no Sudão (S/RES/1706). A partir da Líbia, no entanto, foram deliberadas 46 outras resoluções remetendo à norma ${ }^{41}$ (até agosto de 2016). Quando se fala em responsabilidade internacional em conflitos humanitários, a R2P então passa a ser elemento argumentativo chave.

As iniciativas de potências emergentes também mostraram que a R2P não havia morrido. Na verdade, buscava-se seu aprimoramento institucional. Nesse sentido, dois documentos são paradigmáticos: Responsabilidade ao Proteger $\left(\mathrm{RwP}^{42}\right)$ e Responsible Protection. $\mathrm{O}$ primeiro deles lançado pelo Brasil, na esteira da intervenção na Líbia. O segundo publicado por um think tank ligado ao ministério das Relações Exteriores chinês.

Os dois documentos indicam que, não obstante o uso da força para a proteção de civis em crises humanitárias ser visto com ceticismo, a noção de que há uma responsabilidade internacional nesse tipo de situação está plenamente institucionalizada. Ambas as publicações são reflexo disso. Elas revelam mais uma tentativa de ajuste (modelagem normativa), do que uma rejeição da R2P.

$\mathrm{Na}$ RwP, o Brasil reafirma a R2P e procura oferecer diretrizes para a sua aplicação (Brasil, 2011). Na RP (CIIS, 2012), toda a crítica existente não é quanto à responsabilidade internacional em crises humanitárias, mas o mau uso da norma no tocante às práticas intervencionistas. Nesses dois documentos, a R2P se mostra como estrutura normativa basilar para questões que envolvem responsabilidade internacional e conflitos humanitários.

Ademais, mesmo com o ceticismo em relação ao uso da força, ela não foi descartada em nenhuma das duas iniciativas. No caso brasileiro, é explicito que suas diretrizes estão relacionadas à prática, dos oito parâmetros e procedimentos apresentados no documento,

\footnotetext{
41 Informações disponíveis em: http://www.responsibilitytoprotect.org/index.php/about-rtop/ the-un-and-rtop

42 Abreviação do termo em inglês: Responsibility while Protecting.
} 
quatro deles são diretamente voltados ao uso da força ( (c), (d), (e) e (f)) (Brasil, 2011) . No caso da RP, mesmo sendo um documento muito mais crítico à ideia, ele não nega a possibilidade - não obstante devendo ser evitada ao máximo (CIIS, 2012). Demonstra-se assim a consolidação da faculdade de intervenção militar em torno da R2P inclusive perante Estados céticos.

Os testes da Líbia e da Síria revelam desafios para as questões normativas que permeiam a responsabilidade internacional em crises humanitárias domésticas. Por outro lado, também apontam que, de fato, houve um ajuste entre essa responsabilidade e o arcabouço normativo em volta do instituto da soberania.

\section{Conclusão}

O presente artigo mapeou o ajuste institucional entre responsabilidade internacional e soberania na ONU, rastreando aos movimentos de contenção a partir do do Sul Global. Nesse sentido, deu-se particular atenção ao problema do uso da força.

$\mathrm{Na}$ primeira parte, apresentou-se o processo pelo qual crises humanitárias em conflitos domésticos passaram ser consideradas assuntos de segurança internacional no âmbito do Conselho de Segurança. Percebeu-se, não obstante os progressos, que esses novos ajustes normativos seguiram em um ambiente de contestação por parte de Estados do Sul Global. Ações de países como Rússia e China tornaram-se ilustrativas. A responsabilidade internacional ganhava espaço, mas a ideia de que a soberania foi relativizada - a ponto de o uso da força ser considerado uma opção normal - foi desafiada ao longo do período.

A segunda seção tratou da evolução institucional da R2P, da sua emergência até a consolidação na ONU. Viu-se que esta norma política se tornou uma espécie de ponto focal para as discussões envolvendo o ajuste entre responsabilidade internacional em crises humanitárias internas e soberania. A partir dela, nota-se que não se pode mais afirmar que os governos são os únicos responsáveis por seus cidadãos e que a sociedade internacional não tem responsabilidade de agir em graves catástrofes humanitárias. 
De modo geral, por meio da R2P, foi possível verificar a sedimentação da responsabilidade internacional em casos de conflito humanitário. Surgiu, em torno dessa norma, um modelo estruturado para dar sentido a essa noção de responsabilidade, um fórum específico para debates sobre a matéria e de direcionamento institucional para sua implementação.

Contudo, viu-se que o avanço da R2P é permeado por diversos tipos de contestações. De fato, não se trata de uma institucionalização harmônica. Mas as resistências hoje se concentram em aspectos específicos concernentes à operacionalização do uso da força. Esta faculdade que, não obstante ter se tornado legítima, enfrenta questionamentos sobre a melhor maneira de aplicá-la.

Em suma, é possível inferir que não há mais discussão sobre a existência ou não de uma responsabilidade internacional em crises humanitárias domésticas. A soberania não é mais um elemento legítimo para fundamentar argumentações que justifiquem a negligência da sociedade internacional. Porém, existe ainda um hiato significativo entre a legitimidade e a prática efetiva, principalmente quando interesses geopolíticos estão no cerne das questões. É um processo lento e gradual de ajuste.

\section{Referências}

BADIE, Bertrand. (2002). La diplomatie des droits de l'homme. Paris: Fayard.

BELLAMY, Alex. (2009). "Realizing the Responsibility to Protect". International Studies Perspectives, v. 10, n. 2, p. 111-128.

BELLAMY, Alex. (2006). "Whither the Responsibility to Protect? Humanitarian Intervention and the 2005 World Summit". Ethics \& International Affairs, v. 20, n. 02, p. 143-169.

BERTI, B. (2013). "Forcible intervention in Libya: revamping the 'politics of human protection'?" Global Change, Peace \& Security, v. 26, n. 1, p. 21-39.

BOBBIO, Norberto; MATTEUCCI, Nicola; PASQUINO, Gianfranco. (1998). Dicionário de Política, v. 1. Trad. Carmen C, Varriale (et all) 11 a ed. Brasília: Editora Universidade de Brasília. 
BRASIL. (2011). Responsibility while Protecting (RwP). http://www. responsibilitytoprotect.org/index.php/component/content/ article/35-r2pcs-topics/5758-brazils-statements-on-rtop-from2009-to-present. [Acesso em 15 de maio de 2017].

BUZAN, Barry. (2015). “The English School: a neglected approach to International Security Studies”. Security Dialogue, v. 46, n. 2, p. 126-143.

BUZAN, Barry; HANSEN, Lene. (2009). The Evolution of International Security Studies. Cambridge: Cambridge University Press.

CIIS (2012). Responsible Protection (RP). Disponível em: http:// www.ciis.org.cn/english/2012-06/15/content_5090912.htm. [Acesso em 10 de agosto de 2017].

DONNELLY, Jack. (1999). “The Social Construction of International Human Rights", published in DUNNE, Tim and WHEELER, Nicholas J., Human Rights in Global Politics. Cambridge: Cambridge University Press.

EVANS, Gareth. (2008). The responsibility to protect. Washington.: Brookings Institution Press.

FINNEMORE, Martha. (2003). The purpose of intervention. Ithaca: Cornell University Press.

FRANCK, T. M. (2003). "Interpretation and Change in the Law of Humanitarian Intervention", in: J.L. Holzgrefe \& R.O. Keohane (eds.), Humanitarian Intervention: Ethical, Legal and Political Dilemmas. Cambridge, UK; New York: Cambridge University Press, p. 204-231.

GLANVILLE, Luke. (2014). Sovereignty and the responsibility to protect: a new history. Chicago: The University of Chicago Press. HURD, Ian. (2011). "Is Humanitarian Intervention Legal? The Rule of Law in an Incoherent World," Ethics and International Affairs, v. 25, n. 3, p. 293-313.

ICISS. (2001). The Responsibility to Protect: Report of the International Commission on Intervention and State Sovereignty. Ottawa: International Development Research Centre. 
JACKSON, Robert H. (1995). "The Political Theory of International Society", in: Ken Booth and Steve Smith (eds.), International Relations Theory Today. Philadelphia: Pennsylvania State University Press, p. 110-128.

JACKSON, Robert; SORENSEN, Georg. (2007). Introdução às Relações Internacionais. Rio de Janeiro: Zahar Editora.

KALDOR, Mary. (2007). Human Security: Reflections on Globalization and Intervention. Cambridge: Polity Press.

LUCK, Edward. (2011). "The Responsibility to Protect: The First Decade". Global Responsibility to Protect, v. 3, n. 4, p. 387-399.

MORRIS, Justin. (2013). "Libya and Syria: R2P and the spectre of the swinging pendulum". International Affairs, v. 89, n. 5, p. 1265-1283.

MORRIS, Nicholas. (2006). "Humanitarian Intervention in the Balkans". In Jennifer M. Welsh, ed., Humanitarian Intervention and International Relations. Oxford: Oxford University Press.

ONU. (2004). A More Security World: Our Share Responsibility. . (2009). Assembleia Geral: Resolução 308. Index: A/RES/63/308. . (1991). Conselho de Segurança: Resolução 688. Index: S/ $\mathrm{RES} / 688$.

. (1992a). Conselho de Segurança: Resolução 770. Index: S/ $\mathrm{RES} / 770$.

. (1992b). Conselho de Segurança: Resolução 794. Index: S/ RES794.

. (1994). Conselho de Segurança: Resolução 929. Index: S/ RES/929.

. (1999a). Conselho de Segurança: Resolução 1199. Index: S/ $\mathrm{RES} / 1199$.

. (2006). Conselho de Segurança: Resolução 1674. Index: S/ $\mathrm{RES} / 1674$.

. (2011). Conselho de Segurança: Resolução 1973. Index: S/ $\mathrm{RES} / 1973$.

(1992c). Conselho de Segurança: Reunião 3106. Index: S/ PV.3106. 


\section{PV.3145.}

(1992d). Conselho de Segurança: Reunião 3145. Index: S/

. (1999b). Conselho de Segurança: Reunião 3989. Index: S/ PV.3989.

. (2005a). Conselho de Segurança: Reunião 5319. Index: S/ PV.5319.

. (1965). Declaration on the Inadmissibility of Intervention in the

Domestic Affairs of States and the Protection of Their Independence and Sovereignty. Index: A/RES/2131(XX)

. (2005b). Summit Outcome Document. Index: A/60/L.1.

ONUF, Nicholas Greenwood. (1971). "The Principle of Nonintervention, the United Nations, and the International". International Organization, v. 25, n. 2, p. 209-227.

PU Xiaoyu. (2012). "Socialisation as a Two-way Process: Emerging Powers and the Diffusion of International Norms". The Chinese Journal of International Politics, v. 5, n. 4, 2012, p. 341-367.

STUENKEL, Oliver. (2014). "The BRICS and the Future of R2P: Was Syria or Libya the Exception?”. Global Responsibility to Protect, v. 6, n. 1, p. 3-28.

STUENKEL, Oliver; TOURINHO, Marcos. (2014). "Regulating intervention: Brazil and the responsibility to protect". Conflict, Security Development, v. 14, n. 4, p. 379-402.

THAKUR, Ramesh; WEISS, Thomas. (2009), T. R2P: "From Idea to Norm-and Action?”. Global Responsibility to Protect, v. 1, n. 1, p. 22-53.

WHEELER, Nicholas. (2000). Saving strangers. New York: Oxford University Press.

WEISS, Thomas. (2006).” R2P After 9/11". Wisconsin International Law Journal, v. 24, n. 3, p. 741-760.

WELSH, Jennifer. (2014). "Implementing the Responsibility to Protect: Catalyzing Debate and Building Capacity”. In: BETTS, A.; ORCHARD, P, eds. Implementation and World Politics: How International Norms Change Practice. Oxford: Oxford University Press. 
WILLIAMS, Paul D; BELLAMY, Alex. (2012). "Principles, Politics, and Prudence: Libya, the Responsibility to Protect, and the Use of Military Force”. Global Governance, v. 18, p. 273-297.

ZÄHRINGER, Natalie. (2013). Norm evolution within and across the African Union and the United Nations: The Responsibility to Protect (R2P) as a contested norm". South African Journal of International Affairs, v. 20, n. 2, p. 187-205.

\section{Resumo}

Este artigo mapeia o processo de ajuste institucional-normativo entre responsabilidade internacional em crises humanitárias e soberania, rastreando os movimentos de contenção de Estados do Sul Global no que concerne ao uso da força. O artigo possui três metas específicas. A primeira delas é descrever a emergência, no Conselho de Segurança das Nações Unidas, da ideia de que crises humanitárias internas são assunto de segurança internacional. A segunda é descrever sistematicamente o processo de evolução institucional da norma política chamada de Responsabilidade de Proteger, até a sua consolidação na ONU. A terceira cuida em apontar os movimentos de resistência ao longo do período estudado, a partir das contestações advindas de Estados do Sul Global. A partir de um desenho de pesquisa qualitativo, o artigo levanta os principais documentos envolvendo esse processo combinando seus dados com análises de fontes secundárias. Ao final, é possível ter uma visão geral estruturada das nuanças que perpassam o ajuste entre responsabilidade internacional em conflitos domésticos e soberania.

Palavras-chave: Soberania; Crises humanitárias; Uso da Força; Responsabilidade de Proteger; Sul Global.

\section{Abstract}

This article maps the institutional-normative adjustment between international responsibility in humanitarian crises and sovereignty, tracing the contestation movements coming from the Global South regarding the use of force. It has three specific goals. The first is to describe the rise of the idea that internal humanitarian crises are a matter of international security at the United Nations Security Council. The second is to describe the institutional evolution of the political norm called Responsibility to Protect, from its inception to its consolidation at the UN. The third is to 
identify the movements of resistance throughout the period, based on the contestations of non-western states. Through a qualitative research design, the article evaluates the main documents involving this process, combining the data with secondary sources approaches. In the end, it is possible to have a structured overview of the nuances which characterize the fit between international responsibility in domestic conflicts and sovereignty.

Keywords: Sovereignty; Humanitarian crises; Use of Force; Responsibility to Protect; Global South.

Recebido em 19 de dezembro de 2018 Aprovado em 11 de novembro de 2019 